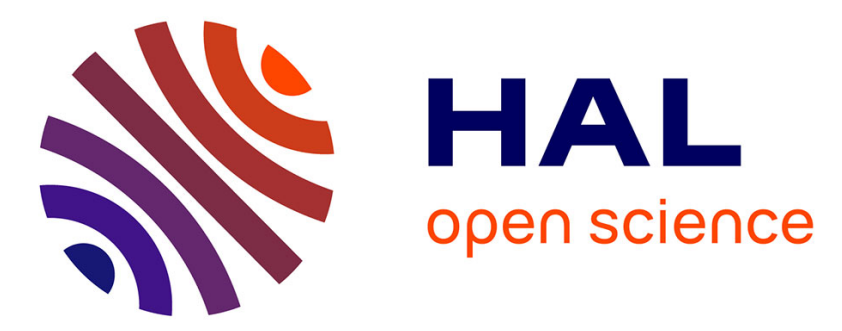

\title{
Decentralised Coordination of Intelligent Autonomous Batteries
}

Evgeny Nefedov, Valeriy Vyatkin

\section{To cite this version:}

Evgeny Nefedov, Valeriy Vyatkin. Decentralised Coordination of Intelligent Autonomous Batteries. 7th Doctoral Conference on Computing, Electrical and Industrial Systems (DoCEIS), Apr 2016, Costa de Caparica, Portugal. pp.425-433, 10.1007/978-3-319-31165-4_40 . hal-01438270

\section{HAL Id: hal-01438270 \\ https://hal.inria.fr/hal-01438270}

Submitted on 17 Jan 2017

HAL is a multi-disciplinary open access archive for the deposit and dissemination of scientific research documents, whether they are published or not. The documents may come from teaching and research institutions in France or abroad, or from public or private research centers.
L'archive ouverte pluridisciplinaire HAL, est destinée au dépôt et à la diffusion de documents scientifiques de niveau recherche, publiés ou non, émanant des établissements d'enseignement et de recherche français ou étrangers, des laboratoires publics ou privés.

\section{(c)(1)}

Distributed under a Creative Commons Attribution| 4.0 International License 


\title{
Decentralised Coordination of Intelligent Autonomous Batteries
}

\author{
Evgeny Nefedov ${ }^{1}$, Valeriy Vyatkin ${ }^{1,2}$, \\ ${ }^{1}$ Aalto University, Dept. of Electrical Engineering and Automation, Helsinki, Finland \\ ${ }^{2}$ Luleå University of Technology, Dept. Of Computer Science, Electrical and Space \\ Engineering, Luleå, Sweden \\ evgeny.nefedov@aalto.fi, vyatkin@,ieee.org
}

\begin{abstract}
This paper proposes enabling intelligence for cyber-physical system of intelligent collaborating energy storages. Two intelligent batteries coordinate their behaviour in a dynamic electricity price scenario, accumulating the energy when the electricity price is low, and replacing the grid when the price is high. Both batteries directly exchange their state information with each other without any centralized processing agent, following the coordination algorithm developed in this paper. This simplifies their integration and enables achieving more optimal behaviour with regards to state of their charge. When one battery is depleted, the other one immediately compensates the losses by a higher discharge rate. Such a distributed coordination approach enables plug-and-play formation of system of batteries, demonstrates the efficiency of such formation and allows for reduction of costs due to longer discharge time of the batteries.
\end{abstract}

Keywords: intelligent battery; energy management; battery monitoring, plugand-play, multi-agent coordination.

\section{Introduction}

Battery energy storage is expected to play a major role in Smart Grid systems, providing more flexibility and efficiency to the grid. Storing the energy, it is possible to use efficiently energy generated by renewable sources, reducing costs and decreasing the load on the electrical grid [1]. One possible source of energy storage capacity is parking lots of hybrid and electric vehicles. However, such systems are highly dynamic in their structure: cars are joining and leaving parking lots regularly. Besides, such systems of batteries are highly heterogeneous in their technical parameters, state of charge, schedules and intentions of their owners.

There exist approaches of forming energy storages from such batteries [2], but a typical coordination concept is that every battery coordinates its activity with a management centre, which has access to the utility and market data. In the present paper, another, peer-to-peer coordination mechanism between system components as embedded agents is proposed. The agents that represent individual batteries take into account own schedule and conditions. One possible implementation of this concept is that each battery has its own embedded control system, which interfaces a barebones battery, and communicates (e.g. via the Internet) with other batteries, utility and 
market data. The research question, driving this study is whether decentralised decision-making in such distributed energy resource systems can bring substantial economic benefits and how to measure them. Removing the central aggregator is the feature that leads to more independent role of each battery in the system, which improves flexibility and adaptability of the energy storage. Another application of the same approach could be in seamless integration of the household battery storages.

\section{Contribution to Cyber-Physical Systems}

The intelligence and methods of collaboration for networking systems in automation are developing for several years and can be found in literature, for example in [3]. As one of the practical applications, communication between power system components for rapid supply restoration was presented in [4]. These works, among others, refer to the Internet of Energy as the future energy distribution environment, enabled by the Internet communication technologies and cyber-physical systems theory. Still, the effective use of renewable energy resources is impossible without efficient energy storages. The current battery technologies are still quite costly to make the renewable energy a dominant source. To achieve affordability of energy storages, this paper proposes to use available batteries, e.g. of electric vehicles, or standard batteries with low residual cost. Enhanced by the appropriate sensing, control and communication infrastructure, large sets of such devices can represent reliable energy storages of substantial capacity. Such sets will be dynamically changing their structure; therefore, self-configuration algorithms must be developed to support dynamic reconfiguration of such distributed storage systems. Each of the batteries is equipped with embedded control device that coordinates its activity with the other such devices of the peers, forming a cyber-physical energy storage system.

The paper investigates application scenarios of the proposed cyber-physical energy storage in the Internet of Energy. The considered system is relatively simple and controls mainly the State of Charge (SOC) parameter; nevertheless, it first demonstrates the operability of suggested peer-to-peer communication between batteries as physical systems. The future development assumes monitoring of more parameters with the consequent use of more complex algorithms.

\section{Related Works}

In recent years, various researches have been carried out at building the intelligent service for using batteries. Plug-In Electric Vehicles technology is the perspective example, where intelligent services and scheduling may have a large impact on the efficiency of such vehicles [5]. A role of energy storage was investigated also for large systems with other energy sources, like photovoltaic panels [6] or wind farm [7], where batteries balance the load smoothing out an intermittent energy profile.

The work of battery management system (BMS) has been studied for several years. It can be presented, for example, as a layered structure for battery state, monitoring and management with mutual data flow between those layers [8]. Some commercial BMS products for electric and hybrid vehicles were compared and summarized by 
Xing et al. [9]. Waag et al. [10] did the essential review concerning battery monitoring. Estimation of battery parameters, as SOC is critical to control the work of the battery, methods for such estimation were observed in the same paper. The battery monitoring algorithm has to satisfy certain requirements, such as consider battery characteristics, limitations due to operation conditions, hardware characteristics, influences of load profile and common requirements on automotive software.

The challenge of battery management is to operate the batteries in a most effective way, considering the above-mentioned constrains. Control approaches in energy management have been studied for many years. Vega et al. [11] reviewed the existing home energy management models, with various coordination approaches between participants. For example, algorithms based on stochastic game theory [12], or service-oriented architecture [13] were observed. Home energy management mechanism considering primarily the state of involved batteries was also studied [14]. The related works, however, do not follow the Internet of Things architecture with batteries communicating to each other; this paper attempts to bridge this gap.

\section{Problem Formulation and Case Study}

The mechanism of composing energy storage is investigated for a simple household application. Each participating battery is assumed to have own controller, which plays role of a communication agent in addition to the charge control. The battery controller has to monitor battery's SOC through current-voltage measurements. The SOC value updates frequently and is used as an input data for the BMS. For brevity, further in this article by interaction of two batteries is meant interaction of their BMSs.

The main structure of the test system is shown in Fig. 1. Each battery gets utility data from the grid and demand data from the consumer, and, in addition, receives the state (remaining capacity) data from the other battery. BMS determines own charge and discharge mode based on all these data. Since the main objective of the paper is first to demonstrate working mechanism of battery coordination, some simplifications are used. Thus, only two batteries are considered. The model also neglects the state of health estimation and therefore costs related to battery aging.

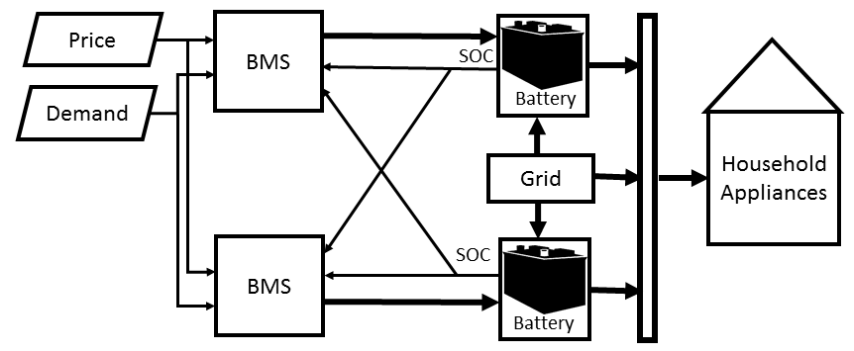

Fig. 1. The layout of the proposed model.

A two-level Matlab Simulink model is proposed. The low-level component is an electric scheme of battery connection. The load, represented as a resistor, must be supplied from the battery during discharge, or otherwise directly from the grid, which 
is assumed to be a DC voltage source. In the latter case, battery also consumes energy for recharging. Current controllers drive the current to supply the load and to recharge the battery, and work as switches, holding and controlling the circuit in the correct state. Those controllers are regulated by external signals from BMS.

State of the battery is monitored via the voltage measurements, which enable estimation of the battery's depth of discharge, and accordingly the SOC. The voltage $V$ changes with the SOC, and is not a constant value. Therefore, it must be measured to control the current $I$, which is related to the electric power $P$ with the relationship $I$ $=P / V$. The value of power provided to the load is determined based on consumer's demand. The charge current to the batteries is constant; however, it automatically decreases when the SOC is close to a higher threshold.

The high-level component is the embedded BMS, determining the operation mode of the battery. The BMS is modelled in Simulink Stateflow mode, and represents a hierarchical state chart directly derived from the operating principle. To satisfy the energy demand from the customer $E_{d e m}$, the following equality must hold all the time:

$$
E_{\text {dem }}=E_{g t l}+E_{\text {disch }} \text {, }
$$

where $E_{g t l}$ is the energy taken from the grid, hereinafter grid-to-load. $E_{\text {disch }}$ is the energy to be extracted from the batteries and consists of two components, as follows:

$$
E_{\text {disch }}=E_{B 1}+E_{B 2} \text {, }
$$

where $E_{B 1}$ is the energy taken from the current battery; $E_{B 2}$ is the energy from the other one. As seen from (1), the customer's load should be supplied either from batteries or directly from the grid. Factors determining a source of power to the load are the utility price $p$ and states of charge of both batteries: $S O C_{l}$ means the state of the current battery; $\mathrm{SOC}_{2}$ is the state of the second battery.

Despite the fact that BMS gets the data from all batteries in the model, each of them is responsible to control only the own battery. Thus, the operating principles further are shown for the single BMS, although they also contain the parameters and symbols related to another battery. The assumption made, that in normal condition (when all the batteries are in the working SOC range) the load is distributed evenly on them, so that $E_{B I}=E_{B 2}$. In other words, all BMSs generate commands $E_{e x}$ to use a certain amount of energy from the battery or from the grid, in normal SOC range $E_{e x}$ $=E_{d e m} / 2$, but all the time the total energy should be equal to $E_{d e m}$.

The following hierarchy of modes is used:

1) Normal or high $\mathrm{SOC}_{2}$ (when $\mathrm{SOC}_{2}>0.2$ )

a) Normal $S_{\text {OCC }}$ (when $0.2<S O C_{1}<=0.9$ )

i. If $p>3$ : demand is satisfied from the battery $\left(E_{e x}=E_{B I}=E_{d e m} / 2\right)$

ii. If $p<=3$ : demand is satisfied directly from the grid $\left(E_{e x}=E_{g t /} / 2\right)$; and battery is being charged

b) Low $S O C_{1}$ (when $S O C_{1}<=0.2$ )

i. If $p>3$ : no command; all demand should be satisfied from the other battery $\left(E_{e x}=0\right)$

ii. If $p<=3$ : demand is satisfied directly from the grid $\left(E_{e x}=E_{g t} / 2\right)$; and battery is being charged

c) High $S O C_{l}$ (when $S O C_{l}>0.9$ )

i. If $p>3$ : demand is satisfied from the battery $\left(E_{e x}=E_{B I}=E_{d e m} / 2\right)$

ii. If $p<=3$ : demand is satisfied directly from the grid $\left(E_{e x}=E_{g t} / 2\right)$ 
2) Low $\mathrm{SOC}_{2}$ (when $\mathrm{SOC}_{2}<=0.2$ )

a) Normal $\mathrm{SOC}_{1}$ (when $0.2<\mathrm{SOC}_{1}<=0.9$ )

i. If $p>3$ : all demand is satisfied from the battery $\left(E_{e x}=E_{B 1}=E_{d e m}\right)$

ii. If $p<=3$ : demand is satisfied directly from the grid $\left(E_{e x}=E_{g t l} / 2\right)$; and battery is being charged

b) Low $S O C_{1}$ (when $S O C_{1}<=0.2$ )

i. If $p>3$ : demand is satisfied directly from the grid $\left(E_{e x}=E_{g t} / 2\right)$

ii. If $p<=3$ : demand is satisfied directly from the grid $\left(E_{e x}=E_{g t l} / 2\right)$; and battery is being charged

c) High $S O C_{l}$ (when $S O C_{l}>0.9$ )

i. If $p>3$ : all demand is satisfied from the battery $\left(E_{e x}=E_{B 1}=E_{d e m}\right)$

ii. If $p<=3$ : demand is satisfied directly from the grid $\left(E_{e x}=E_{g t /} / 2\right)$

A case study of a household with quite standard power demand and connected batteries is presented in this paper. The electricity price values were chosen based on MISO (Midcontinent Independent System Operator, Inc.) hourly price data [15], and vary between 1.9 and 4.9 cents for $\mathrm{kWh}$. The customer's demand values are taken from hourly energy consumption data of a sample household in [16]. Price and demand values repeat every 24 hours and their variations are shown in Fig. 2.

A system of two identical NiMH batteries was modelled. Both are fully charged initially, i.e. $S O C=1$. In normal SOC range, battery charges during low-price periods, and discharges when the price is high. If SOC is lower than 0.2 , discharging process stops, and conversely, if SOC value is higher than 0.9 the battery should stop charging to avoid the negative effects related to overcharge [17]. To evaluate the interchangeability of the batteries, one of them switches off periodically. This emulates the case when the user needs to take the battery out for any other purposes. When such an extraction takes place, BMS assigns the SOC value to zero and no charge-discharge operations are possible until next switching-on. It is assumed that the real SOC stays unchanged during this time. To evaluate the results, two different scenarios studied. In scenario 1, batteries work independently, and each of them is responsible to supply its own half of demand. In scenario 2 , those batteries use the coordination algorithm above to replace each other when needed.

\section{Results and Discussion}

Fig. 3 shows two plots for the SOC of the batteries: left for scenario 1, and right for scenario 2, for 72 hours period. SOC decreases when the price value from Fig. 2 is greater than 3 cents $/ \mathrm{kWh}$, and increases when the price is getting equal or lower than 3 cents/kWh, which represents battery's charge-discharge operations. At some point, when the first battery becomes inactive, it can no longer supply the load until reconnected. Such transition can be seen in Fig. 3 (left) at time moment $40 \mathrm{~h}$, for example. The second battery is still able to provide energy, and it continues to discharge. In scenario 1, when only one battery is working, the demand is satisfied by taking a half from the second battery, and a half from the grid. 

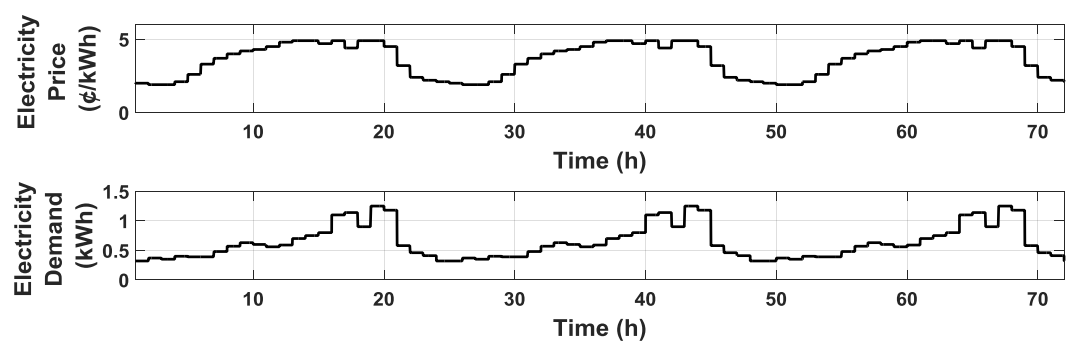

Fig. 2. Price and customer's demand profiles, used in simulations.
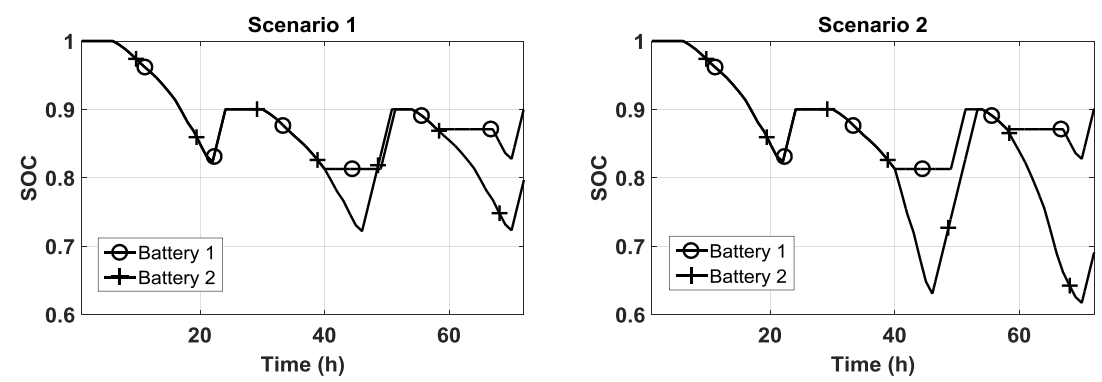

Fig. 3. SOC of the batteries in scenario 1 (left) and scenario 2 (right).

In Scenario 2, when such extraction of the first battery occurs, the second one reacts with producing more energy. It continues to provide its previous "normal" amount of energy, but now its task is also to give energy for another inactive battery. This is reflected in Fig. 3 (right): at the same time moment $40 \mathrm{~h}$, SOC of the second battery starts to decrease faster, and this difference with scenario 1 is the result of the work for two batteries. When price value becomes lower than $3 \phi / \mathrm{kWh}$, the connected batteries use this opportunity for recharging, and their SOC values are getting higher. In the considered case, both batteries are able to restore the full SOC ( $90 \%$ threshold) before next discharge (i.e. next period of high-price).

Fig. 4 shows energy consumption from the grid for two scenarios. The grid-to-load line repeats demand profile given in Fig. 2 when both batteries are inactive, and becomes zero when they are being discharged. When batteries work on the scenario 1 , a half of the required energy is also taken from the grid when the first battery switches off, regardless of the price. However, in Scenario 2 grid-to-load line repeats demand profile only when the price is less than $3 \notin / \mathrm{kWh}$. Thereby, regardless of the demand, all duration of high-price periods is covered by the energy stored in batteries. Only when the second battery also becomes not available, due to either extraction or depletion, the grid will start to supply all the demand. It can happen with higher energy consumption or using the batteries with less capacity.

The economical profit of using batteries is presented on Fig. 5. It captured three cost cases. The first one is the cost if no battery is used, i.e. the integrated cost of the product of the price and consumption if the demand is supplied directly from the grid. The other two cases are the costs for the considered scenarios, i.e. the consumption in the form of grid-to-load plus recharging of the batteries. In Scenario 1, the profit from the use of batteries amounted to $5.56 \$$ for 30 days period. It is clear that the longer 
the battery can be discharged during high-price periods, the greater the total costs difference. In scenario 2, avoiding the necessity of buying electricity by higher price for a longer time, the effect of the presence of the batteries becomes even greater than before. The results demonstrated an additional saving of $1.75 \$$ for a month period comparing with scenario 1 , or about $13 \%$; and total profit of $7.31 \$$ with respect to the case when the batteries are not used at all. However, since the model neglects all kinds of losses related to the energy flowing in and out of the batteries, the real savings will be a bit less. The profit may be greater or lower depending on battery capacity, electricity prices and demand value.

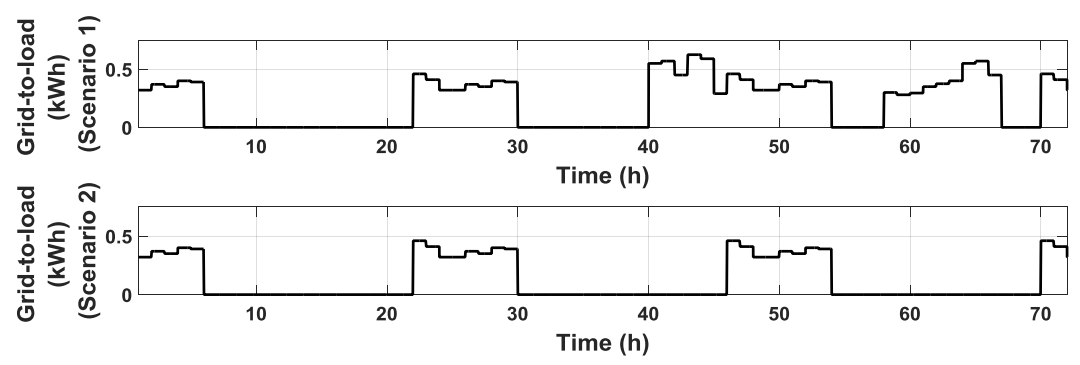

Fig. 4. Grid-to-load profiles comparison between scenario 1 and scenario 2 .

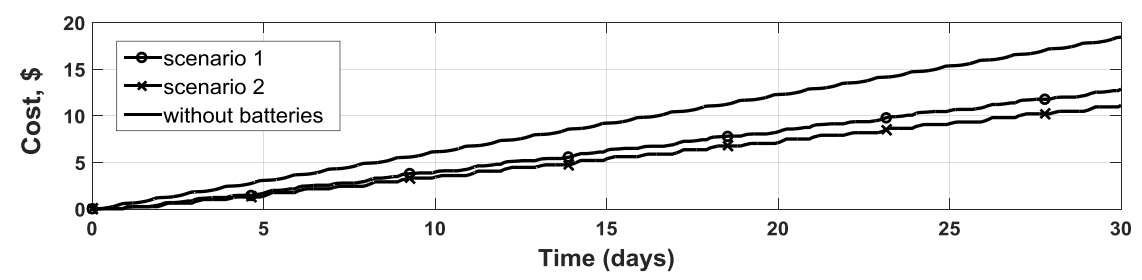

Fig. 5. Costs comparison between scenario 1 and scenario 2 .

\section{Conclusion}

A new energy storage control principle is proposed, based on plug-and-play integration of multiple intelligent batteries with behaviour emerging from the collaboration of components. Such coordination was illustrated on a simulated example with two batteries and compared with the case when batteries work independently. The results demonstrate the efficiency of the approach to the direct interaction between batteries. Such decentralized concept could be implemented, for example, using embedded microcontrollers with network connectivity. Mutual interchangeability allows increasing total working time of the batteries, and therefore a significant cost reduction due to maximizing of battery usage as an energy source during periods with high electricity prices.

Future related research is planned in such directions as achieving scalability, functional completeness of such battery constellations, theoretical estimation of limitations and parameters of their performance. The ongoing work also includes real validation of the proposed algorithm. Practically it is planned to develop a prototype 
laboratory implementation of an intelligent battery and demonstrate the scenarios of their coalition formation in particular Internet of Energy applications.

\section{References}

1. Wade, N.S., Taylor, P.C., Lang, P.D., Jones, P.R.: Evaluating The Benefits of an Electrical Energy Storage System in a Future Smart Grid. Energy policy, 38, pp. 7180--7188 (2010)

2. Lukic, S.M., Cao, J., Bansal, R.C., Rodriguez, F., Emadi, A.: Energy Storage Systems for Automotive Applications. IEEE Trans. Industrial Electronics, 55(6), pp. 2258--2267 (2008)

3. Colombo, A., Karnouskos, S., Bangemann, T.: A System of Systems View on Collaborative Industrial Automation. In: 2013 IEEE International Conference on Industrial Technology (ICIT), pp. 1968--1975 (2013)

4. Zhabelova, G., Vyatkin, V., Dubinin, V.: Towards Industrially Usable Agent Technology for Smart Grid Automation. IEEE Trans. Industrial Electr., 62(4), pp. 2629--2641 (2015)

5. Honarmand, M., Zakariazadeh, A., Jadid, S.: Optimal Scheduling of Electric Vehicles in an Intelligent Parking Lot Considering Vehicle-to-Grid Concept and Battery Condition. Energy, 65, pp. 572--579 (2014)

6. Delfanti, M., Falabretti, D., Merlo, M.: Energy Storage for PV Power Plant Dispatching. Renewable Energy, 80, pp. $61--72$ (2015)

7. Teleke, S., Baran, M.E., Huang, A.Q., Bhattacharya, S., Anderson, L.: Control Strategies for Battery Energy Storage for Wind Farm Dispatching. In: IEEE transactions on energy conversion, vol. 24, no. 3, pp. 725--732 (2009)

8. Meissner, E., Richter, G.: Battery Monitoring and Electrical Energy Management Precondition for Future Vehicle Electric Power Systems. Journal of Power Sources, 116, pp. 79--98 (2003)

9. Xing, Y., Ma, E.W.M., Tsui, K.L., Pecht, M.: Battery Management Systems in Electric and Hybrid Vehicles. In: Energies, 4, pp. 1840--1857 (2011)

10.Waag, W., Fleischer, C., Sauer, D.U.: Critical Review of the Methods for Monitoring of Lithium-Ion Batteries in Electric and Hybrid Vehicles. Journal of Power Sources, 258, pp. 321--339 (2014)

11.Vega, A.M., Santamaria, F., Rivas, E.: Modeling for Home Electric Energy Management: A review. In: Renewable and Sustainable Energy Reviews, 52, pp. $948--959$ (2015)

12.Das, S.K., Roy, N., Roy, A.: Context-Aware Resource Management in Multi-Inhabitant Smarthomes: a Framework Based on Nash H-Learning. In: Pervasive and Mobile Computing, 2, pp. 372--404 (2006)

13.Chehri, A., Mouftah, H.T.: Service-Oriented Architecture for Smart Building Energy Management. In: Proceedings of the IEEE ICC 2013 - selected areas in communications symposium, Budapest, pp. $4099--4103$ (2013)

14.Boynuegri, R., Yagcitekin, B., Bays, M., Karakas, A., Uzunoglu, M.: Energy Management Algorithm for Smart Home With Renewable Energy Sources. In: Proceedings of the 4th International conference on power engineering, energy and electrical drives, Istanbul, pp. 1753--1758 (2013)

15.Power Smart Prices, Ameren Illinois Co., May 2015, http://www.powersmartpricing.org/prices/?date $=20150506$

16.Ardakanian, O., Koochakzadeh, N., Singh, R.P., Golab, L., Keshav, S.: Computing Electricity Consumption Profiles from Household Smart Meter Data. In: Proceedings of EDBT/ICDT Workshops (EnDM), pp.140--147 (2014)

17.Zhu, W.H., Zhu, Y., Tatarchuk, B.J.: Self-Discharge Characteristics and Performance Degradation of Ni-MH Batteries for Storage Applications. International journal of hydrogen energy, 39, pp. 19789--19798 (2014) 